\title{
Curcumin induces the apoptosis of non-small cell lung cancer cells through a calcium signaling pathway
}

\author{
XUDONG XU, DA CHEN, BO YE, FANGMING ZHONG and GANG CHEN \\ Department of Thoracic Surgery, Hangzhou Red Cross Hospital, Hangzhou, Zhejiang 310000, P.R. China
}

Received October 4, 2014; Accepted February 5, 2015

DOI: $10.3892 / \mathrm{ijmm} .2015 .2167$

\begin{abstract}
Curcumin is known for its anti-proliferative effects in lung cancer cells. Studies have demonstrated that an increase in the levels of intracellular free calcium $\left(\left[\mathrm{Ca}^{2+}\right] \mathrm{i}\right)$ is involved in curcumin-induced apoptosis. In this study, we aimed to investigate the involvement of calcium overload in the antiproliferative effects of curcumin on lung cancer cells and the possible mechanisms involved. A549 and H1299 lung cancer cells were incubated with serial diluted curcumin. MTT assay was used to assess the cytotoxic effects of curcumin on the lung cancer cells; the inositol 1,4,5-trisphosphate receptor (IP3R, a key regulator of $\left[\mathrm{Ca}^{2+}\right]$ i signaling) was blocked by its specific inhibitor, xestospongin C (XSC). Hoechst 33342, Fura-2/AM and rhodamine 123 fluorescence staining was employed to detect the apoptosis, the $\left[\mathrm{Ca}^{2+}\right] \mathrm{i}$ level and mitochondrial potential in the lung cancer cells. The expression levels of B-cell lymphoma-2 (Bcl-2), cleaved caspase-3 and cleaved caspase-9, and the phosphorylation level of IP3R were evaluated by western blot analysis. Our results revealed that curcumin inhibited cell growth, increased the $\left[\mathrm{Ca}^{2+}\right] \mathrm{i}$ level and increased the apoptosis of the lung cancer cells in a concentration-dependent manner. However, XSC attenuated the increase in the $\left[\mathrm{Ca}^{2+}\right]$ $\mathrm{i}$ level and apoptosis, and also reversed the curcumin-induced loss of mitochondrial potential potential. Treatment with curcumin downregulated the expression of Bcl-2, and elevated the phosphorylation level of IP3R in a concentration-dependent manner. However, this effect was not reversed by treatment with XSC. In conclusion, the cytotoxic effects of curcumin on lung cancer cells were induced by calcium overload, which involves Bcl-2 mediated IP3R phosphorylation.
\end{abstract}

\section{Introduction}

Lung cancer is the most common type of cancer of the respiratory system, with a 5-year overall survival rate of $<15 \%$ (1).

Correspondence to: Dr Xudong Xu, Department of Thoracic Surgery, Hangzhou Red Cross Hospital, 208 Huancheng East Road, Hangzhou, Zhejiang 310000, P.R. China

E-mail: xudong_xu_rc@126.com

Key words: curcumin, lung cancer, apoptosis, calcium
Due to its malignant tendency and the high rate of recurrence and metastasis, the effects of surgical treatment are limited (2). Similar to other types of cancer cells, lung cancer cells are also characterized by the features of sustained proliferation and resistance to cell apoptosis. Non-small cell lung cancer (NSCLC) is responsible for approximately $85 \%$ of the total lung cancer cases. The prognosis is pessimistic as NSCLC is not sensitive to the majority of conventional cytotoxic treatments, such as chemotherapy and radiotherapy (3). Thus, the need for the identification of novel alternative therapeutic drugs for NSCLC is urgent and of significance.

Apoptosis, also known as programmed cell death, is believed to be triggered by multiple extra- and intracellular factors. Osmotic pressure imbalance, reactive oxygen species (ROS), mitochondrial damage and calcium overload have been shown to play an important role in the initiation and regulation of apoptosis (4). Calcium is one of the small signaling molecules regulating various biological functions in cells. Cell cycle regulation and cell death have been suggested to closely correlate with the intracellular calcium ion $\left(\left[\mathrm{Ca}^{2+}\right] \mathrm{i}\right)$ concentration (5). Under pathological conditions, such as ischemia-reperfusion injury and oxidative stress, the $\left[\mathrm{Ca}^{2+}\right] \mathrm{i}$ level has been reported to markedly increase in many types of cells. This condition is known as calcium overload, which eventually leads to the activation of pro-apoptotic factors, resulting in apoptosis $(6,7)$.

The endoplasmic reticulum (ER) is considered the critical organelle participating in multiple cellular biological functions. Accumulating evidence indicates that in response to pathological stimuli, the ER decides the cell fate by initiating cell defense or activating apoptosis $(8,9)$. It has been reported that calcium is released from the ER to induce calcium overload, leading to cell death (10). Located in the ER membrane, the inositol 1,4,5-trisphosphate receptor (IP3R) has been suggested to be involved in the regulation of cellular calcium homeostasis, playing a role as the main calcium release channel in the majority of cells (11). B-cell lymphoma-2 (Bcl-2) belongs to the family of anti-apoptotic proteins and is located in the ER. Accumulating evidence has indicated that the Bcl-2 protein plays a role in regulating the phosphorylation status of IP3R. It appears that the phosphorylation of IP3R is reduced by Bcl-2 and thus the IP3R-induced calcium release (IICR) is impaired (12).

Curcumin has a long medical application history in Traditional Chinese Medicine (TCM) since the ancient times. Curcumin is extracted from turmeric (Curcuma longa L.) and 
is known as 1,7-bis(4-hydroxy-3-methoxyphenyl)-1,6-heptadiene-3,5-dione in modern pharmacology. In several recent studies, the suppression of Bcl-2 expression has been suggested to be involved in the apoptosis-inducing effects of curcumin on NSCLC (13). Furthermore, curcumin has been reported to induce cell apoptosis by increasing the $\left[\mathrm{Ca}^{2+}\right] \mathrm{i}$ level (14). However, whether calcium overload-induced cell apoptosis is involved in the anti-proliferative effects of curcumin has not yet been elucidated. Thus, in the present study, we examined our hypothesis that curcumin exacerbates IICR by suppressing $\mathrm{Bcl}-2$ expression, thus inducing the apoptosis of NSCLC cells.

\section{Material and methods}

Cell lines and treatment. The human lung cancer cell lines, A549 and H1299, were provided by American Type Culture Collection (ATCC; Manassas, VA, USA). The cells were cultured in RPMI-1640 medium (HyClone, Logan, UT, USA) supplemented with $10 \%$ fetal bovine serum (FBS; Gibco, Carlsbad, CA, USA), $250 \mathrm{ng} / \mathrm{ml}$ amphotericin B, $100 \mathrm{~g} / \mathrm{ml}$ streptomycin, $100 \mathrm{U} / \mathrm{ml}$ penicillin and $2 \mathrm{mmol} / 1$ glutamine (all from Sigma, St. Louis, MO, USA) in culture flasks (Corning Inc., Corning, NY, USA) which were maintained in a an incubator under a humidified environment with $5 \% \mathrm{CO}_{2}$ and $95 \%$ fresh air. In order to determine the cytotoxicity of curcumin, the cells were treated with serially diluted curcumin (Sigma) at concentrations of $0,10,20,30,40,50,60,70$ and $80 \mu \mathrm{mol} / 1$ for $24 \mathrm{~h}$. In order to examine the role of IP3R, a specific IP3R inhibitor, xestospongin C (XSC; Sigma) was used to pre-treat the cancer cells at a concentration of $10 \mu \mathrm{mol} / 1$ for $15 \mathrm{~min}$ to block IP3R.

Cell viability assay. The viabilities of the A549 and H1299 cells were assessed by a colorimetric 3-(4,5-dimethylthiazol2-yl)-2,5-diphenyltetrazolium bromide (MTT) assay. Briefly, $1 \times 10^{5}$ cells were plated in a 96-well plate and then incubated with curcumin at different concentrations $(0-80 \mu \mathrm{mol} / \mathrm{l})$ for $24 \mathrm{~h}$. After being washed with sterilized phosphate-buffered saline (PBS; Bioss, Beijing, China), the cells were incubated with MTT solution (Sigma) at a concentration of $5 \mathrm{mg} / \mathrm{ml}$ for $4 \mathrm{~h}$. The cells were then dissolved by dimethyl sulfoxide (DMSO; Sigma). The amount of formed formazan crystals was investigated by measuring the absorbance value at $540 \mathrm{~nm}$ using a plate reader (Bio-Rad, Hercules, CA, USA).

Measurement of cell apoptosis. Cell apoptosis was evaluated by Hoechst 33342 staining. The cells were collected, washed and fixed in $4 \%$ paraformaldehyde for $20 \mathrm{~min}$. The cells were stained with Hoechst 33342 (Sigma) at a final concentration of $10 \mu \mathrm{mol} / 1$ for $20 \mathrm{~min}$ in a dark chamber. The cells were then observed under a fluorescence microscope (Carl Zeiss, Jena, Germany). Captured images were analyzed using Image-Pro Plus software (Media Cybernetics, Rockville, MD, USA). The amount of Hoechst positively stained cells was used to indicate the percentage of apoptosis.

Determination of the $\left[\mathrm{Ca}^{2+}\right]$ i concentration. The $\left[\mathrm{Ca}^{2+}\right] \mathrm{i}$ level in the A549 and H1299 cells was determined by Fura-2/AM fluorescence staining. Briefly, the harvested cells were incubated with Fura-2/AM (Beyotime Institute of Biotechnology, Shanghai, China) at final concentration of $5 \mu \mathrm{mol} / 1$ at $30^{\circ} \mathrm{C}$ for $30 \mathrm{~min}$. A fluorescence microscope (Carl Zeiss) was then used to observe the cells. The $\left[\mathrm{Ca}^{2+}\right]$ i level was represented by the mean fluorescence intensity (MFI) after the captured images were analyzed using Image-Pro Plus software (Media Cybernetics).

Evaluation of mitochondrial membrane potential $\left(\Delta \Psi_{m}\right)$. In order to detect the $\Delta \Psi \mathrm{m}$, the collected cells were incubated with rhodamine 123 (Sigma) at final concentration of $10 \mathrm{mg} / \mathrm{l}$ at $37^{\circ} \mathrm{C}$ for $30 \mathrm{~min}$ in a dark chamber. The fluorescence of rhodamine 123 was detected using a FACSCalibur flow cytometer (BD Biosciences, San Jose, CA, USA) at $530 \mathrm{~nm}$. The fluorescence of rhodamine 123 represented the levels of $\Delta \Psi \mathrm{m}$.

Western blot analysis. The harvested cells were washed with PBS and lysed in RIPA buffer system (Santa Cruz Biotechnology, Inc. Santa Cruz, CA, USA) on ice. Following centrifugation at $12,000 \mathrm{x}$ g at $4^{\circ} \mathrm{C}$ for $10 \mathrm{~min}$, the supernatant separated from the lysates was considered as the extracted total protein. The protein concentration was detected using the BCA kit (Thermo Scientific, Rockford, IL, USA) according to the manufacturer's instructions. A total of $20 \mu \mathrm{g}$ of protein were loaded and separated by electrophoresis on $10-15 \%$ sodium dodecyl sulfate-polyacrylamide gels (SDS-PAGE) and then transferred onto PVDF membranes electronically. Non-specific binding was eliminated by incubation with $0.05 \%$ Tween-20 and $5 \%$ defatted milk. Specific antibodies against IP3R (Abcam, Cambridge, MA, USA), phosphorylated (p-)IP3R (Ser1756; Cell Signaling Technology, Inc., Beverly, MA, USA), Bcl-2 (Abcam), cleaved caspase-3, cleaved caspase-9 (both from Santa Cruz Biotechnology, Inc.) and GAPDH (Invitrogen, Carlsbad, CA, USA) were used to incubate the membranes at $4^{\circ} \mathrm{C}$ for $8-12 \mathrm{~h}$. The immunoblots were detected by corresponding horseradish peroxidase-conjugated secondary antibodies (Invitrogen) using the enhanced chemiluminescence kit (Amersham Pharmacia Biotech, Piscataway, NJ, USA). The intensities of the immunoblots were analyzed by Image-Pro Plus software (Media Cybernetics).

\section{Results}

Curcumin inhibits the proliferation of A549 and H1299 cells. The inhibitory effects of crucumin on the growth of cancer cells were determined by MTT assay. As demonstrated in Fig. 1, curcumin suppressed the growth of the A549 and H1299 cells in a concentration-dependent manner. Curcumin began to exert cytotoxic effects on the A549 cells at a concentration of $50 \mu \mathrm{mol} / 1$, while the H1299 cells appeared to be more sensitive to curcumin, which began to exert cytotoxic effects at a concentration of $40 \mu \mathrm{mol} / \mathrm{l}$. Thus, the concentrations of 50,60 and $70 \mu \mathrm{mol} / 1$ curcumin were selected to incubate the A549 cells, while the concentrations of 40,50 and $60 \mu \mathrm{mol} / 1$ curcumin were selected to incubate the H1299 cells.

IP3R inhibitor impairs the curcumin-induced apoptosis of A549 and H1299 cells. Fig. 2 shows the captured images of Hoechst 33342 fluorescence staining of the A459 and H1299 cells. Following incubation with serially diluted curcumin, the apoptosis of both the A549 and H1299 cells significantly increased in a concentration-dependent manner. However, 


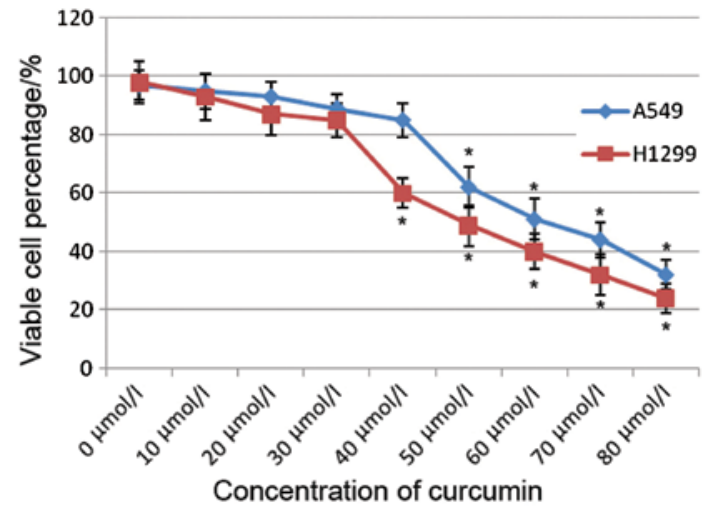

Figure 1. Curcumin inhibits the growth of A549 and H1299 lung cancer cells. Line chart demonstrates the results from MTT assay. The blue line indicates the viable percentage of A549 cells incubated with serially diluted curcumin at concentrations of $0,10,20,30,40,50,6070$ and $80 \mu \mathrm{mol} / 1$ for $24 \mathrm{~h}$. The red line indicates the viable percentage of $\mathrm{H} 1299$ cells incubated with serially diluted curcumin at concentrations of $0,10,20,30,40,50,6070$ and $80 \mu \mathrm{mol} / 1$ for $24 \mathrm{~h}$. Values are presented as the means $\pm \mathrm{SD}$. Indicates that the difference is significant when compared with the previous concentration $\left({ }^{*} \mathrm{P}<0.05\right)$. in the XSC pre-treated A549 and H1299 cells, the apoptosis induced by curcumin was significantly attenuated.

The $\left[\mathrm{Ca}^{2+}\right] \mathrm{i}$ concentration is elevated by treatment with curcumin, but this effect is reversed by pre-treatment with XSC in the A549 and H1299 cells. The images of Fura-2/AM staining of the A549 and H1299 cells are shown in Fig. 3. As a calcium indicator, the intensities of Fura-2/AM staining were used to determine the $\left[\mathrm{Ca}^{2+}\right] \mathrm{i}$ concentration. Trreatment with curcumin significantly elevated the $\left[\mathrm{Ca}^{2+}\right]$ i levels in both the A549 and H1299 cells in a concentration-dependent manner. However, following pre-treatment with XSC, the curcumininduced increase in the $\left[\mathrm{Ca}^{2+}\right] \mathrm{i}$ level was impaired.

Protective effect of XSC on the curcumin-induced decrease in $\Delta \Psi \mathrm{m}$ in the $\mathrm{A} 549$ and $H 1299$ cells. The flow cytometric assessment of rhodamine 123 staining was used to examine the $\Delta \Psi \mathrm{m}$ level. The decrease in $\Delta \Psi \mathrm{m}$ indicated the increased permeability and impaired integrity of the mitochondrial membrane

A

A549
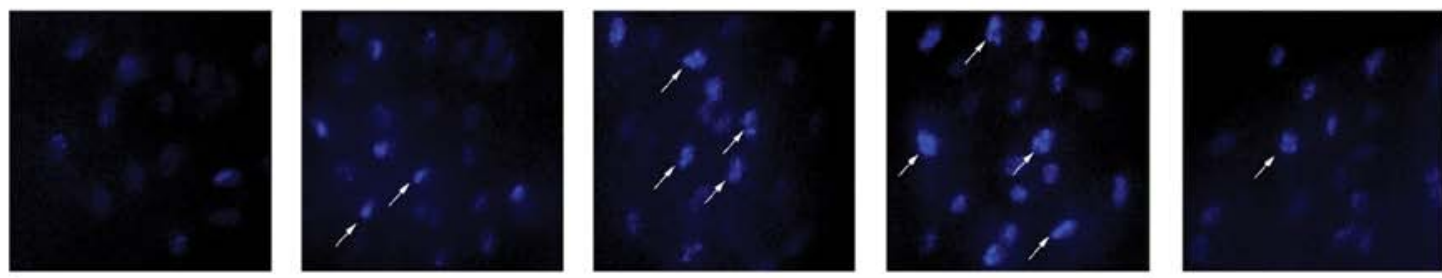

Curcumin concentrations $0 \mu \mathrm{mol} / \mathrm{l}$

$50 \mu \mathrm{mol} / \mathrm{l}$
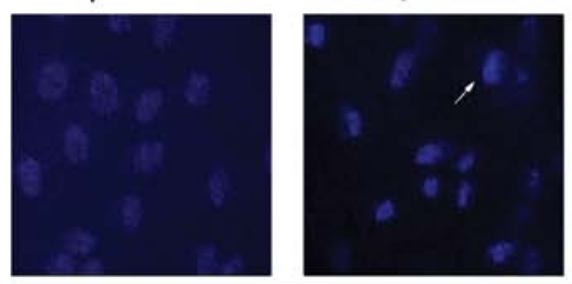

Curcumin concentrations

$0 \mu \mathrm{mol} / \mathrm{l}$

$40 \mu \mathrm{mol} / \mathrm{l}$

B

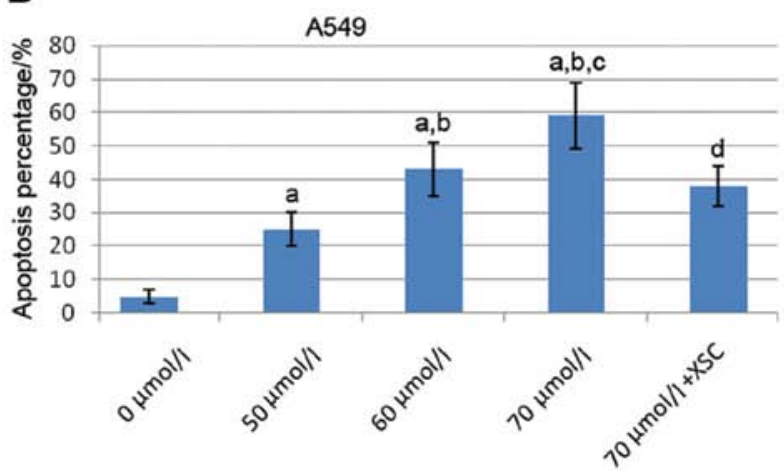

$60 \mu \mathrm{mol} / \mathrm{l}$

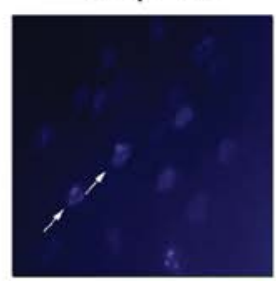

$50 \mu \mathrm{mol} / \mathrm{l}$

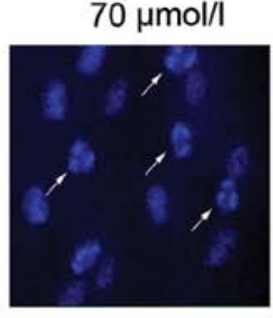

$60 \mu \mathrm{mol} / \mathrm{l}$
$70 \mu \mathrm{mol} / \mathrm{I}+\mathrm{XSC}$

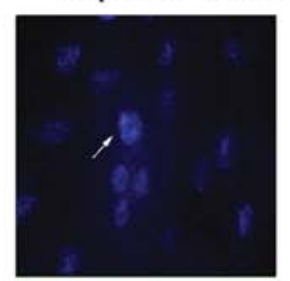

$60 \mu \mathrm{mol} / \mathrm{I}+\mathrm{XSC}$

C

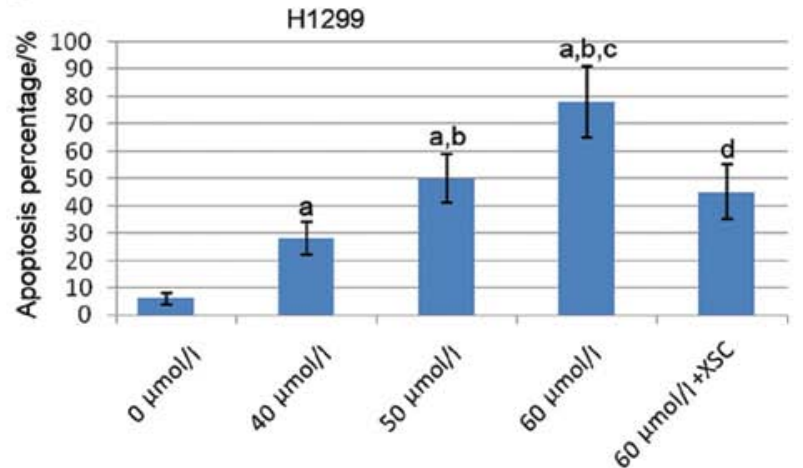

Figure 2. Effects of curcumin and xestospongin C (XSC) on the apoptosis of A549 and H1299 lung cancer cells; 0,50,60 and $70 \mu \mathrm{mol} / \mathrm{lindicate}$ A549 cells incubated with curcumin at concentrations of 0,50,60 and $70 \mu \mathrm{mol} / 1$, respectively for $24 \mathrm{~h} ; 70 \mu \mathrm{mol} / 1+\mathrm{XSC}$ indicates XSC-pre-treated A549 cells incubated with curcumin at $70 \mu \mathrm{mol} / 1$ for $24 \mathrm{~h} ; 0,40,50$ and $60 \mu \mathrm{mol} / 1$ indicate $\mathrm{H} 1299$ cells incubated with curcumin at concentrations of $0,40,50$ and $60 \mu \mathrm{mol} / 1$, respectively for $24 \mathrm{~h} ; 60 \mu \mathrm{mol} / 1+$ XSC indicates XSC-pre-treated H1299 cells incubated with curcumin at $60 \mu \mathrm{mol} / 1$ for $24 \mathrm{~h}$. (A) Captured fluorescence images of A549 and $\mathrm{H} 1299$ cells stained with Hoechst 33342. White arrows indicate apoptotic cells. Columns in (B and C) indicate apoptotic the percentage of A549 cells and H1299 cells. a, Differences are significantly different when compared with $0 \mu \mathrm{mol} / \mathrm{l} ; \mathrm{b}$, differences are significantly different when compared with $50 \mu \mathrm{mol} / 1$ (or $40 \mu \mathrm{mol} / 1$ for H1299 cells); c, differences are significantly different when compared with $60 \mu \mathrm{mol} / 1$ (or $50 \mu \mathrm{mol} / 1$ for H1299); d, differences are significantly different when compared with $70 \mu \mathrm{mol} / 1$ (or $60 \mu \mathrm{mol} / 1$ for H1299 cells). 
A
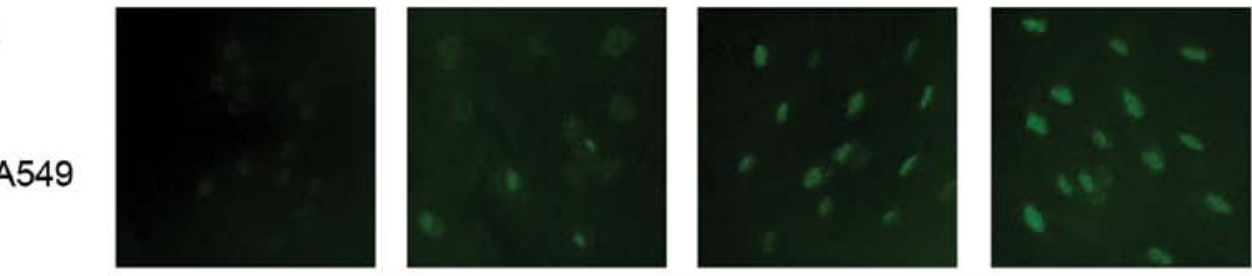

Curcumin concentrations $0 \mu \mathrm{mol} / \mathrm{l}$

$50 \mu \mathrm{mol} / \mathrm{l}$
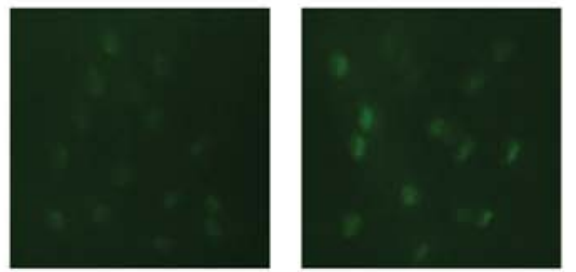

Curcumin concentrations

$0 \mu \mathrm{mol} / \mathrm{l}$

$40 \mu \mathrm{mol} / \mathrm{l}$

B
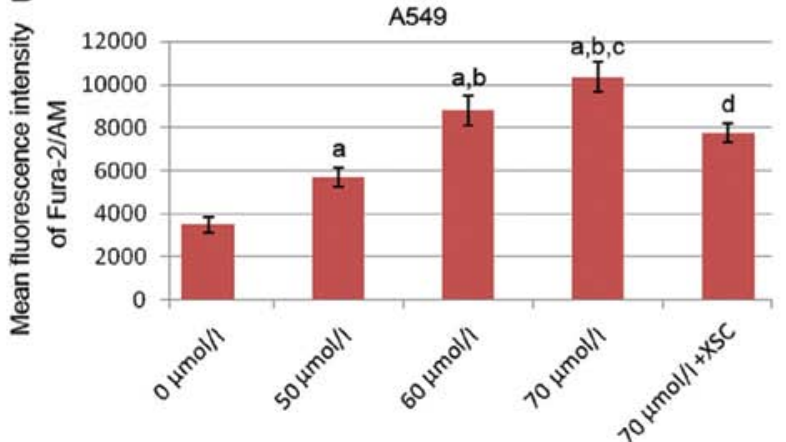

$60 \mu \mathrm{mol} / \mathrm{l}$

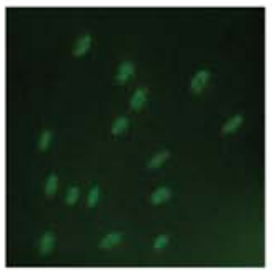

$50 \mu \mathrm{mol} / \mathrm{l}$
$70 \mu \mathrm{mol} / \mathrm{l}$

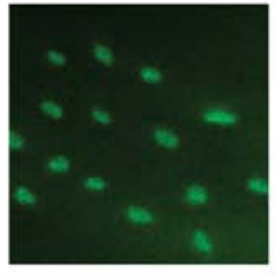

$60 \mu \mathrm{mol} / \mathrm{l}$

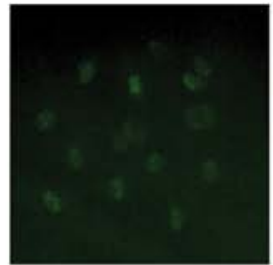

$70 \mu \mathrm{mol} / \mathrm{I}+\mathrm{XSC}$

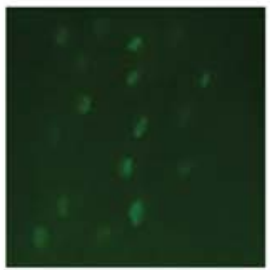

$60 \mu \mathrm{mol} / \mathrm{l}+\mathrm{XSC}$

C

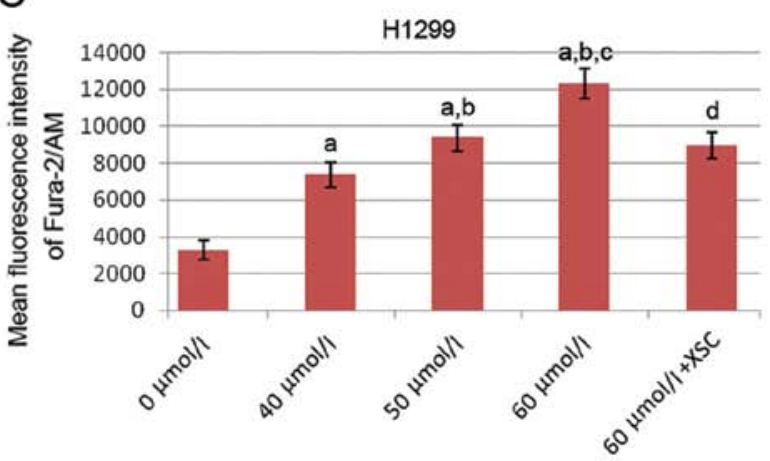

Figure 3. Effects of curcumin and xestospongin C (XSC) on intracellular free calcium [Ca $\left.{ }^{2+}\right]$ l levels in A549 and $\mathrm{H} 1299$ lung cancer cells; 0,50, 60 and $70 \mu$ mol/ 1 indicate A549 cells incubated with curcumin at concentrations of 0,50,60 and $70 \mu \mathrm{mol} / 1$, respectively for $24 \mathrm{~h} ; 70 \mu \mathrm{mol} / 1+\mathrm{XSC}$ indicates XSC-pre-treated A549 cells incubated with curcumin at $70 \mu \mathrm{mol} / 1$ for $24 \mathrm{~h} ; 0,40,50$ and $60 \mu \mathrm{mol} / 1$ indicate $\mathrm{H} 1299$ cells incubated with curcumin at concentrations of $0,40,50$ and $60 \mu \mathrm{mol} / 1$ respectively for $24 \mathrm{~h} ; 60 \mu \mathrm{mol} / 1+\mathrm{XSC}$ indicates XSC-pre-treated $\mathrm{H} 1299$ cells incubated with curcumin at $60 \mu \mathrm{mol} / 1$ for $24 \mathrm{~h}$. (A) The [Ca $\left.{ }^{2+}\right] \mathrm{i}$ level was detected by Fura-2/AM fluorescence staining. Positively stained calcium is shown as green zones in the captured images under a microscope. Columns in (B and C) indicate the mean fluorescence intensity of Fura-2/AM in A549 cells and H1299 cells. a, Differences are significantly different when compared with $0 \mu \mathrm{mol} / 1$; b, differences are significantly different when compared with $50 \mu \mathrm{mol} / 1$ (or $40 \mu \mathrm{mol} / 1$ for H1299 cells); c, differences are significantly different when compared with $60 \mu \mathrm{mol} / \mathrm{l}$ (or $50 \mu \mathrm{mol} / 1$ for $\mathrm{H} 1299$ cells); d, differences are significantly different when compared with $70 \mu \mathrm{mol} / 1$ (or $60 \mu \mathrm{mol} / 1$ for H1299 cells).

which was considered as a pro-apoptotic event. Treatment with curcumin decreased the $\Delta \Psi \mathrm{m}$ in both the A549 and H1299 cells in a concentration-dependent manner (Fig. 4). However, the XSC pre-treated A549 and H1299 cells showed a distinct resistance to the curcumin-induced decrease in $\Delta \Psi \mathrm{m}$.

Effect of curcumin on Bcl-2 expression and IP3R phosphorylation. Fig. 5 illustrates the immunoblots of Bcl-2, IP3R and p-IP3R in the curcumin-treated A549 and H1299 cells. We found that the expression of $\mathrm{Bcl}-2$ was reduced by treatment curcumin in a concentration-dependent manner. We also found that the phosphorylation of IP3R was enhanced by treatment with curcumin in a concentration-dependent manner. Pre-treatment with XSC failed to affect the changes in Bcl-2 expression and IP3R phosphorylation in the curcumin-treated cells.

Curcumin initiates caspase cascade activation which is reversed by pre-treatment with XSC. Fig. 5 also demonstrates the immunoblots of cleaved caspase- 3 and caspase- 9 in the A549 and H1299 cells. It was found that treatment with curcumin stimulated the expression levels of cleaved caspase-3 and caspase- 9 in a concentration-dependent manner. The cleavage of caspase- 3 and caspase- 9 suggests the activation of caspase cascade, which is generally accepted as the indicator of mitochondrial-dependent apoptosis. However, in the XSC pre-treated A549 and H1299 cells, the activation of the caspase cascade was markedly attenuated.

\section{Discussion}

In the present study, we investigated the anti-proliferative effects of curcumin on NSCLC cells. Two NSCLC cell lines, A549 and H1299, were used in this study. We found that curcumin significantly inhibited the growth of the A549 and H1299 cells in a concentration-dependent manner. The cytotoxic effects of curcumin on lung cancer cells were mediated by the induction of apoptosis. Thus, we further investigated the possible mechanisms involved. For the first time, to the best of our knowledge, our results indicated that the phosphorylation status of IP3R 

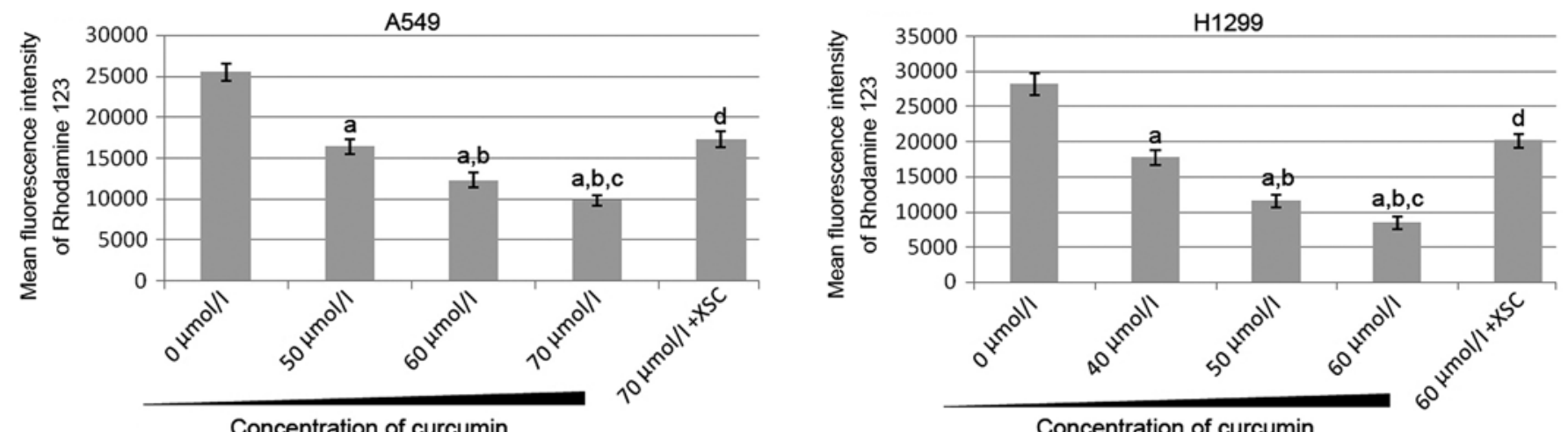

Figure 4. Effects of curcumin and xestospongin $\mathrm{C}(\mathrm{XSC})$ on mitochondrial membrane potential $(\Delta \Psi \mathrm{m})$ in $\mathrm{A} 549$ and $\mathrm{H} 1299$ lung cancer cells; $0,50,60$ and $70 \mu \mathrm{mol} / 1$ indicate A549 cells incubated with curcumin at concentrations of 0,50, 60 and $70 \mu \mathrm{mol} / 1$, respectively for $24 \mathrm{~h} ; 70 \mu \mathrm{mol} / 1+\mathrm{XSC}$ indicates XSC-pretreated A549 cells incubated with curcumin at $70 \mu \mathrm{mol} / 1$ for $24 \mathrm{~h} ; 0,40,50$ and $60 \mu \mathrm{mol} / 1$ indicate $\mathrm{H} 1299$ cells incubated with curcumin at concentrations of 0 , 40, 50 and $60 \mu \mathrm{mol} / 1$, respectively for $24 \mathrm{~h} ; 60 \mu \mathrm{mol} / 1+$ XSC indicates XSC-pre-treated H1299 cells incubated with curcumin at $60 \mu \mathrm{mol} / 1$ for $24 \mathrm{~h}$. Columns on the upper and lower panel show the mean fluorescence intensity of rhodamine 123 staining of A549 and H1299 respectively. Rhodamine 123 is usually used as an indicator stain of $\Delta \Psi \mathrm{m}$. Values are presented as the means $\pm \mathrm{SD}$. a, Differences are significantly different when compared with $0 \mu \mathrm{mol} / \mathrm{l} ; \mathrm{b}$, differences are significantly different when compared with $50 \mu \mathrm{mol} / 1$ (or $40 \mu \mathrm{mol} / 1$ for H1299 cells); c, differences are significantly different when compared with $60 \mu \mathrm{mol} / 1$ (or $50 \mu \mathrm{mol} / 1$ for $\mathrm{H} 1299$ cells); d, differences are significantly different when compared with $70 \mu \mathrm{mol} / 1$ (or $60 \mu \mathrm{mol} / 1$ for H1299 cells).
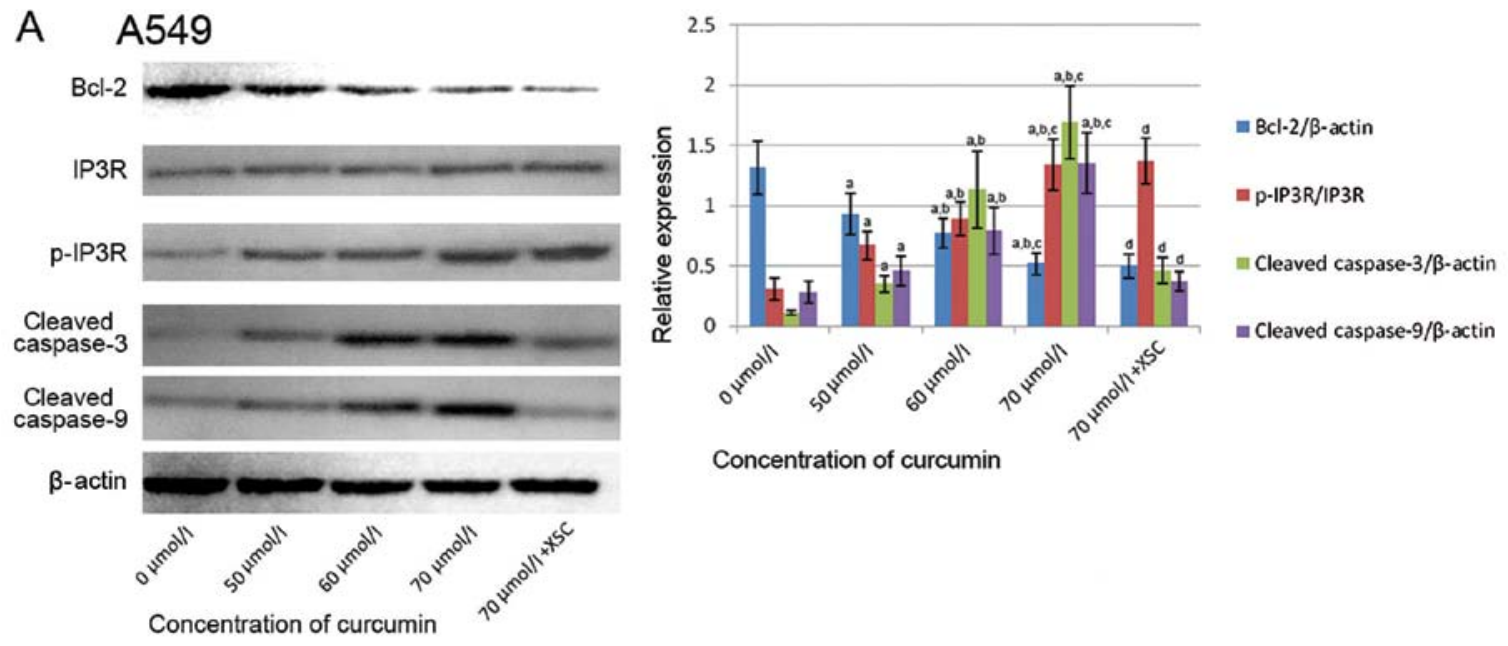

\section{B $\mathrm{H} 1299$}
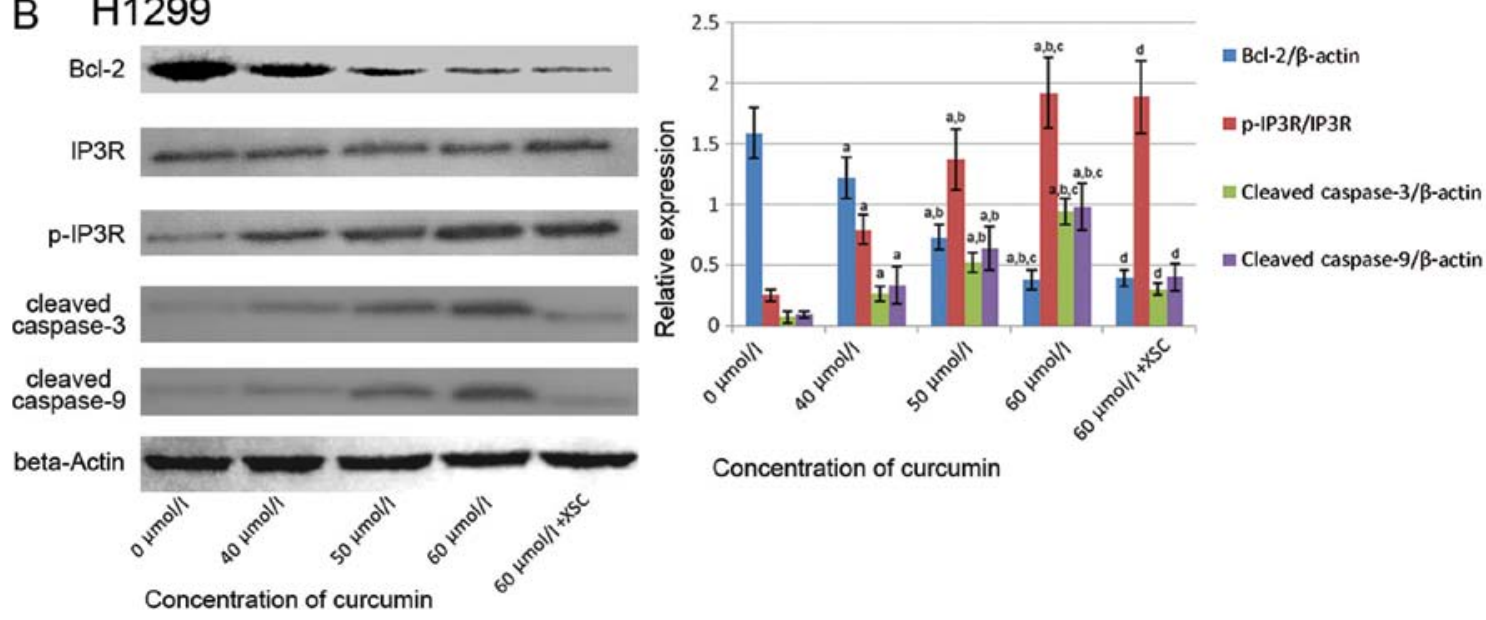

Concentration of curcumin

Figure 5. Effects of curcumin and xestospongin C (XSC) on relative protein expression in A549 and H1299 cells; 0, 50, 60 and $70 \mu \mathrm{mol} / 1$ indicate A549 cells incubated with curcumin at concentrations of $0,50,60$ and $70 \mu \mathrm{mol} / 1$, respectively for $24 \mathrm{~h} ; 70 \mu \mathrm{mol} / 1+\mathrm{XSC}$ indicates XSC-pre-treated A549 cells incubated with curcumin at $70 \mu \mathrm{mol} / 1$ for $24 \mathrm{~h} ; 0,40,50$ and $60 \mu \mathrm{mol} / 1$ indicate $\mathrm{H} 1299$ cells incubated with curcumin at concentrations of $0,40,50$ and $60 \mu \mathrm{mol} / 1$, respectively for $24 \mathrm{~h} ; 60 \mu \mathrm{mol} / 1+\mathrm{XSC}$ indicates XSC-pre-treated $\mathrm{H} 1299$ cells incubated with curcumin at $60 \mu \mathrm{mol} / 1 \mathrm{for} 24 \mathrm{~h}$. The left panels in both (A and B) demonstrated the immunoblots of Bcl-2. Inositol 1,4,5-triphosphate receptor (IP3R), p-IP3R, cleaved caspase-3, cleaved caspase-9 and $\beta$-actin in A549 and H1299 cells. Columns on the right panels in both (A and B) indicate the ratio of Bcl-2/ $\beta$-actin, p-IP3R/IP3R, cleaved caspase-3/ $\beta$-actin and cleaved caspase-9// 3 -actin respectively. a, Differences are significantly different when compared with $0 \mu \mathrm{mol} / \mathrm{l}$; b, differences are significantly different when compared with $50 \mu \mathrm{mol} /$ (or $40 \mu \mathrm{mol} /$ for H1299 cells); c, differences are significantly different when compared with $60 \mu \mathrm{mol} /$ (or $50 \mu \mathrm{mol} /$ for $\mathrm{H} 1299$ cells); d, differences are significantly different when compared with $70 \mu \mathrm{mol} /$ (or $60 \mu \mathrm{mol} /$ for H1299 cells). 
played a crucial role in this mitochondrial-dependent apoptosis machinery.

Due to the inefficiency of conventional anticancer therapies and drugs, the prognosis of NSCLC remains poor. It is tremendously costly and time-consuming and requires much effort to continuously seek for and develop new effective anticancer drugs, as has been over the past decades $(15,16)$. Mother nature may provide promising solutions to this problem. To date, a number of natural products, such as curcumin, resveratrol (17), ginsenosides (18), matrine (19), baicalin (20) have been found to exert potent anticancer effects. Curcumin has been studied since the 1990s and has been shown to exhibit various biological functions, including anti-inflammatory, anti-microbial, anti-fibrotic, antioxidant and anticancer activities (21). Previous studies have indicated that curcumin inhibits the proliferation of many types of human cancer cells $(22,23)$. In this study, we found that significantly curcumin inhibited the proliferation of A549 and H1299 lunc cancer cells in a concentration-dependent manner.

The induction of apoptosis is the most common approach to inhibit the proliferation of cancer cells, which is also recognized as the cytotoxic effect of anticancer reagents. At cytotoxic concentrations, above $50 \mu \mathrm{mol} / 1$ for A549 cells and $40 \mu \mathrm{mol} / 1$ for H1299 cells in the current study, curcumin induced cell apoptosis in a concentration-dependent manner which was evidenced by Hoechst staining. Mitochondrial-dependent apoptosis is known as one of the most common apoptotic pathways (24). At the early stage of apoptosis, there are several featured changes in the dysfunctioned mitochondria. The integrity of the mitochondrial membrane cannot be maintained and then several soluble proteins, such as cytochrome $c$ are released into the cytosol due to increased permeability of the membrane $(25,26)$. This change is characterized by loss of $\Delta \Psi \mathrm{m}$ (27). In the present study, following incubation with curcumin, the $\Delta \Psi \mathrm{m}$ in both the A549 and H1299 cells decreased significantly as the concentration of curcumin increased. After cytochrome $c$ binds with pro-caspase-9 and apoptosis protease activating factor-1 (APAF-1), the apoptosome is formed to cleave caspase- 9 , triggering the activation of the caspase cascade, resulting in cell apoptosis (28). In the present study, the expression levels of cleaved caspase- 3 and cleaved caspase- 9 increased significantly following treatment with curcumin, indicating that the curcumin-induced apoptosis was mitochondrial-dependent.

The intracellular calcium overload may be one of the initiators of mitochondrial-dependent apoptosis (29). In cytosol, the excess accumulation of calcium leads to mitochondrial damage directly and indirectly. Formed calcium phosphate in the mitochondrial matrix interrupts the functions of the respiratory chain, leading to the loss of $\Delta \Psi \mathrm{m}$ (30). Additionally, the activities of some enzymes, such as Mn-superoxide dismutase (MnSOD) and peroxidase are impaired by calcium accumulation, resulting in the excessive production of ROS, which compromises the integrity of the mitochondrial membrane (31). In the present study, we found that the $\left[\mathrm{Ca}^{2+}\right] \mathrm{i}$ concentration in both the A549 and H1299 cells was significantly elevated following treatment with curcumin. This result suggested that the calcium overload induced mitochondrial-dependent apoptosis in the curcumintreated NSCLC cells.
In order to investigate the role of IP3R in curcumin-induced mitochondrial-dependent apoptosis, XSC, a specific inhibitor of IP3R, was used to pre-treat the cells in this study. As shown by our results, the XSC pre-treated A549 and H1299 cells were resistant to curcumin-induced apoptosis. Mechanically, XSC inhibited the increase in the $\left[\mathrm{Ca}^{2+}\right] \mathrm{i}$ level and apoptotic proteins, indicating that IP3R was involved in the calcium overload-induced mitochondrial-dependent apoptosis in the curcumin-treated cells. IP3R is a universal intracellular calcium release channel. The activation of IP3R is considered to be dependent on its phosphorylation status (32). In most cases, IP3R is activated by phosphorylation. IP3R is also believed to be located in the Golgi apparatus, the nuclear envelop and the mitochondrial-associated ER membranes (MAMs), which enables activated IP3R to mediate the direct calcium transfer from the ER to the mitochondria (33).

It is generally accepted that the $\mathrm{Bcl}-2$ protein is antiapoptotic, which inhibits the accumulation and oligomerization of activated Bax and Bak, thus suppressing mitochondrial outer membrane permeabilization (34). Furthermore, Bcl-2 has been shown to play a role in the regulation of calcium release from the ER (35). In a previous study, it was suggested that Bcl-2 acts as a docking protein to facilitate the interaction of IP3R and calcineurin, which then dephosphorylates IP3R, decreasing the channel activity $(36,37)$. In the present study, we found that in the curcumin-treated A549 and H1299 cells, the IP3R phosphorylation was enhanced and Bcl-2 expression was downregulated. The changes in IP3R phosphorylation and Bcl-2 expression were not affected by XSC. These results suggested that the downregulation of $\mathrm{Bcl}-2$ upregulated the phosphorylation of IP3R, thus increasing the IICR following treatment with curcumin.

In the present study, we found that the curcumin-induced NSCLC cell apoptosis was associated with calcium overload, which further induced mitochondrial-dependent apoptosis. Mechanically, the calcium overload in the curcumin-treated NSCLC cells was mediated by IP3R. Bcl-2 may be involved in regulating the phosphorylation status of IP3R. In conclusion, our findings provide new insight, namely that curcumin induces the apoptosis of cancer cells through a calcium signalingmediated pathway.

\section{References}

1. Ike S, Tanaka F, Ueda M, et al: Evaluation of improvement in prognosis in surgical cases of lung cancer based on the 5-year survival rate. Nippon Kyobu Geka Gakkai Zasshi 44: 312-313, 1996 (In Japanese).

2. Hung JJ, Jeng WJ, Hsu WH, Chou TY, Huang BS and Wu YC: Predictors of death, local recurrence, and distant metastasis in completely resected pathological stage-I non-small-cell lung cancer. J Thorac Oncol 7: 1115-1123, 2012.

3. Saisho S, Yasuda K, Maeda A, et al: Post-recurrence survival of patients with non-small-cell lung cancer after curative resection with or without induction/adjuvant chemotherapy. Interact Cardiovasc Thorac Surg 16: 166-172, 2013.

4. Li JH, Yue W, Huang Z, et al: Calcium overload induces C6 rat glioma cell apoptosis in sonodynamic therapy. Int J Radiat Biol 87: 1061-1066, 2011.

5. Nakayama H, Fujio Y and Yamaguchi O: Calcium dependent signaling in cardiac hypertrophy and cell death. Clin Calcium 23: 505-515, 2013 (In Japanese).

6. Seo SR and Seo JT: Calcium overload is essential for the acceleration of staurosporine-induced cell death following neuronal differentiation in PC12 cells. Exp Mol Med 41: 269-276, 2009. 
7. Ma TS: Sarcoplasmic reticulum calcium ATPase overexpression induces cellular calcium overload and cell death. Ann NY Acad Sci 853: 325-328, 1998

8. Johnson GG, White MC and Grimaldi M: Stressed to death: targeting endoplasmic reticulum stress response induced apoptosis in gliomas. Curr Pharm Des 17: 284-292, 2011.

9. He Q, Lee DI, Rong R, et al: Endoplasmic reticulum calcium pool depletion-induced apoptosis is coupled with activation of the death receptor 5 pathway. Oncogene 21: 2623-2633, 2002.

10. Deniaud A, Sharaf el dein O, Maillier E, et al: Endoplasmic reticulum stress induces calcium-dependent permeability transition, mitochondrial outer membrane permeabilization and apoptosis. Oncogene 27: 285-299, 2008

11. Kasumu AW, Liang X, Egorova P, Vorontsova D and Bezprozvanny I: Chronic suppression of inositol 1,4,5-triphosphate receptor-mediated calcium signaling in cerebellar purkinje cells alleviates pathological phenotype in spinocerebellar ataxia 2 mice. J Neurosci 32: 12786-12796, 2012.

12. Rong YP, Aromolaran AS, Bultynck G, et al: Targeting Bcl-2-IP3 receptor interaction to reverse $\mathrm{Bcl}-2$ 's inhibition of apoptotic calcium signals. Mol Cell 31: 255-265, 2008.

13. Puliyappadamba VT, Cheriyan VT, Thulasidasan AK, et al: Nicotine-induced survival signaling in lung cancer cells is dependent on their p53 status while its down-regulation by curcumin is independent. Mol Cancer 9: 220, 2010.

14. Wang WH, Chiang IT, Ding K, et al: Curcumin-induced apoptosis in human hepatocellular carcinoma $\mathrm{j} 5$ cells: Critical role of $\mathrm{ca}(+2)$-dependent pathway. Evid Based Complement Alternat Med 2012: 512907, 2012.

15. Zi X and Zhang R: Anti-cancer molecular targets of natural products. Curr Cancer Drug Targets 13: 485, 2013.

16. Cragg GM, Grothaus PG and Newman DJ: Impact of natural products on developing new anti-cancer agents. Chem Rev 109: 3012-3043, 2009.

17. Sun W, Wang W, Kim J, et al: Anti-cancer effect of resveratrol is associated with induction of apoptosis via a mitochondrial pathway alignment. Adv Exp Med Biol 614: 179-186, 2008.

18. Wang W, Rayburn ER, Hao M, et al: Experimental therapy of prostate cancer with novel natural product anti-cancer ginsenosides. Prostate 68: 809-819, 2008.

19. Liu XY, Ruan LM, Mao WW, Wang JQ, Shen YQ and Sui MH: Preparation of RGD-modified long circulating liposome loading matrine, and its in vitro anti-cancer effects. Int J Med Sci 7: 197-208, 2010.

20. Franek KJ, Zhou Z, Zhang WD and Chen WY: In vitro studies of baicalin alone or in combination with Salvia miltiorrhiza extract as a potential anticancer agent. Int J Oncol 26: 217-224, 2005.

21. Noorafshan A and Ashkani-Esfahani S: A review of therapeutic effects of curcumin. Curr Pharm Des 19: 2032-2046, 2013.

22. Mehta HJ, Patel V and Sadikot RT: Curcumin and lung cancer-a review. Target Oncol: May 21, 2014 (Epub ahead of print).

23. Darvesh AS, Aggarwal BB and Bishayee A: Curcumin and liver cancer: a review. Curr Pharm Biotechnol 13: 218-228, 2012.
24. Jiang L, Liu Y, Ma MM, Tang YB, Zhou JG and Guan YY: Mitochondria dependent pathway is involved in the protective effect of bestrophin-3 on hydrogen peroxide-induced apoptosis in basilar artery smooth muscle cells. Apoptosis 18: 556-565, 2013.

25. Sawai H and Domae N: Release of cytochrome $c$ from mitochondria precedes Bax translocation/activation in Triton X-100-induced apoptosis. Leuk Res 32: 445-453, 2008.

26. Wang S and El-Deiry WS: Cytochrome $c$ : a crosslink between the mitochondria and the endoplasmic reticulum in calciumdependent apoptosis. Cancer Biol Ther 3: 44-46, 2004.

27. Zamzami $\mathrm{N}$ and Kroemer G: Methods to measure membrane potential and permeability transition in the mitochondria during apoptosis. Methods Mol Biol 282: 103-115, 2004.

28. Soengas MS, Alarcon RM, Yoshida H, et al: Apaf-1 and caspase- 9 in p53-dependent apoptosis and tumor inhibition. Science 284: 156-159, 1999.

29. Pinton P, Giorgi C, Siviero R, Zecchini E and Rizzuto R: Calcium and apoptosis: ER-mitochondria $\mathrm{Ca}^{2+}$ transfer in the control of apoptosis. Oncogene 27: 6407-6418, 2008.

30. Kurskii MD, Tugai VA and Fedoriv AN: Effect of serotonin and calcium on separate components of respiratory chain of mitochondria in some rabbit tissues. Ukr Biokhim Zh 42: 584-588, 1970 (In Ukrainian).

31. Komary Z, Tretter L and Adam-Vizi V: Membrane potentialrelated effect of calcium on reactive oxygen species generation in isolated brain mitochondria. Biochim Biophys Acta 1797: 922-928, 2010

32. Vanderheyden V, Devogelaere B, Missiaen L, De Smedt H, Bultynck G and Parys JB: Regulation of inositol 1,4,5-trisphosphate-induced $\mathrm{Ca}^{2+}$ release by reversible phosphorylation and dephosphorylation. Biochim Biophys Acta 1793: 959-970, 2009.

33. Giorgi C, Wieckowski MR, Pandolfi PP and Pinton P: Mitochondria associated membranes (MAMs) as critical hubs for apoptosis. Commun Integr Biol 4: 334-335, 2011.

34. Hahn P, Lindsten T, Ying GS, et al: Proapoptotic bcl-2 family members, Bax and Bak, are essential for developmental photoreceptor apoptosis. Invest Ophthalmol Vis Sci 44: 3598-3605, 2003.

35. Rong YP, Bultynck G, Aromolaran AS, et al: The BH4 domain of Bcl-2 inhibits ER calcium release and apoptosis by binding the regulatory and coupling domain of the IP3 receptor. Proc Natl Acad Sci USA 106: 14397-14402, 2009.

36. Hanson CJ, Bootman MD, Distelhorst CW, Wojcikiewicz RJ and Roderick HL: Bcl-2 suppresses $\mathrm{Ca}^{2+}$ release through inositol 1,4,5-trisphosphate receptors and inhibits $\mathrm{Ca}^{2+}$ uptake by mitochondria without affecting ER calcium store content. Cell Calcium 44: 324-338, 2008

37. Chen R, Valencia I, Zhong F, et al: Bcl-2 functionally interacts with inositol 1,4,5-trisphosphate receptors to regulate calcium release from the ER in response to inositol 1,4,5-trisphosphate. J Cell Biol 166: 193-203, 2004. 